\title{
Morphological assessment of the stylohyoid complex variations with cone beam computed tomography in a Turkish population
}

\author{
C. Buyuk ${ }^{1}$, K. Gunduz ${ }^{2}$, H. Avsever ${ }^{3}$ \\ ${ }^{1}$ Department of Dentomaxillofacial Radiology, Faculty of Dentistry, Okan University, Istanbul, Turkey \\ ${ }^{2}$ Department of Dentomaxillofacial Radiology, Faculty of Dentistry, Ondokuz Mayıs University, Samsun, Turkey \\ ${ }^{3}$ Department of Dentomaxillofacial Radiology, Health Sciences University, Ankara, Turkey
}

Received: 21 April 2017; Accepted: 31 May 2017]

\begin{abstract}
Background: The aim of this investigation was to evaluate the length, thickness, sagittal and transverse angulations and the morphological variations of the stylohyoid complex (SHC), to assess their probable associations with age and gender, and to investigate the prevalence of it in a wide range of a Turkish sub-population by using cone beam computed tomography (CBCT).

Materials and methods: The CBCT images of the 1000 patients were evaluated retrospectively. The length, thickness, sagittal and transverse angulations, morphological variations and ossification degrees of SHC were evaluated on multiplanar reconstructions (MPR) adnd three-dimensional (3D) volume rendering (3DVR) images. The data were analysed statistically by using nonparametric tests, Pearson's correlation coefficient, Student's $t$ test, $\chi^{2}$ test and one-way ANOVA. Statistical significance was considered at $p<0.05$.

Results: It was determined that 684 (34.2\%) of all 2000 SHCs were elongated (> $35 \mathrm{~mm}$ ). The mean sagittal angle value was measured to be $72.24^{\circ}$ and the mean transverse angle value was $70.81^{\circ}$. Scalariform shape, elongated type and nodular calcification pattern have the highest mean age values between the morphological groups, respectively. Calcified outline was the most prevalent calcification pattern in males. There was no correlation between length and the calcification pattern groups while scalariform shape and pseudoarticular type were the longest variations.

Conclusions: We observed that as the anterior sagittal angle gets wider, SHC tends to get longer. The most observed morphological variations were linear shape, elongated type and calcified outline pattern. Detailed studies on the classification will contribute to the literature. (Folia Morphol 2018; 77, 1: 79-89)
\end{abstract}

Key words: styloid, temporal bone, morphology, anatomical variations, ossification, eagle syndrome, cone beam computed tomography

\section{INTRODUCTION}

The styloid process (SP) is a long, thin bony projection emerging from the inferior aspect of the skull base. Its proximal part merges with tympanic plate of the temporal bone, whereas its distal end provides attachments to the muscles and ligaments. The stylopharyngeus, stylohyoid and styloglossus muscles, the stylohyoid and stylomandibular ligaments originate

Address for correspondence: C. Buyuk, DDS, Okan University, Faculty of Dentistry, Department of Dentomaxillofacial Radiology, 34394, Mecidiyeköy/Şişli, Istanbul, Turkey, tel: +90212 21265 26, e-mail: cansubuyuk@yahoo.com 
from the process. These structures regulate the movements of mandible, hyoid bone, tongue and pharynx.

The SP, stylohyoid ligament (SHL) and lesser cornu of the hyoid bone form the stylohyoid chain (SHC). The chain, which connects the temporal bone to hyoid bone, is in close proximity to the significant neurovascular elements. The apex of SP is located between external and internal carotid arteries. The maxillary artery, internal jugular vein, glossopharyngeal nerve, vagus nerve and facial nerve run medial to SHC. The trace of the hypoglossal nerve, cervical sympathetic chain, and ansa cervicalis branches are mainly posterolateral to the SHC $[11,24,30,40]$.

The SHL sometimes ossifies and forms a solid structure. The degree of this ossification is individually variable [41]. The pathogenesis of the SHC ossification is still not well understood. Many authors suggest different theories such as reactive hyperplasia, reactive metaplasia, anatomic variance, aging developmental anomaly and intraligamentary metaplasia $[3,8,31,39]$. The congenital theory, which is the most accepted one, asserts that mechanical stresses may sometimes lead to stretching of the Reichert cartilage and the ossification of SHC during the embryological development of the SP [40].

By compressing the surrounding neurovascular structures, this ossification may lead some symptoms. These symptoms include recurrent throat pain, foreign body sensation, dysphagia or facial pain and are referred as Eagle syndrome, because they were first described by Eagle in 1937. The increased length of the styloid process is one of the pathogenic factors for the onset of the syndrome $[4,7,10,18,22]$. The other factors might be its increased thickness, sagittal and transverse angles and morphological characteristics of the chain. Moreover, Kent et al. [19] suggested that a close relation between the $\mathrm{SHC}$ and the tonsillar fossa may be a predisposing factor, too. These features may present differently in the same patient, so each chain must be assessed separately [2]. Some structures like glossopharyngeal and hypoglossal nerves, internal carotid artery and internal jugular vein may be compressed between the SHC and the atlas when the anterior sagittal angle of the chain gets wider [27, 33, 34]. On the other hand, a long SHC with a narrow anterior sagittal angle may irritate the anatomical structures localised in parapharyngeal space [1]. Furthermore, a narrow transverse angle may lead to some complaints due to the compression of the adjacent structures [2].
The ossified parts of the SHC might be observed in the lateral, lateral oblique, temporomandibular joint radiographs and anteroposterior skull projections [38]. Today, SHC can be displayed with panoramic and cephalometric films, cone beam computed tomography (CBCT) and computed tomography (CT). SP is localised medial to the focal trough on panoramic radiographs, this leads to distortion and magnification on size of it [17, 23]. CBCT images provide more detailed and accurate information about SHC ossification than panoramic images [5].

The aim of this investigation was to evaluate the length, thickness, sagittal and transverse angulations and also the morphological variations of the SHC, to assess their probable associations with age and gender and, additionally, to investigate the prevalence of these variations in a wide range of a Turkish subpopulation by $C B C T$, through conducting dentists and maxillofacial surgeons.

\section{MATERIALS AND METHODS}

The CBCT images of the 1000 patients who were referred to Ondokuz Mayıs University DentoMaxillofacial Radiology Department between 2013 and 2015 for various reason (orthodontic treatment, implant planning, assessment of maxillofacial pathologies) were evaluated retrospectively. Only high-quality images were included. The patients with malformations or foreign bodies in the region of interest were excluded. The study was approved by OMU Clinical Research Ethics Board, number B.30.2.ODM.0.20.08/1632.

All images were obtained by using Galileos (Sirona Dental Systems, Bensheim, Germany) CBCT device with parameters of $98 \mathrm{kVp}, 15-30 \mathrm{~mA}$ and $15 \mathrm{~mm}$ $\times 15 \mathrm{~mm}$ field of view, 2-5 s exposure time and $14 \mathrm{~s}$ scanning time. Acquired data were analysed by using SIRONA Sidexis XG image viewer and the data consisted of 12-bit grey scale depth with a $0.25 \mathrm{~mm}^{3}$ isotropic voxel size. Digital images were examined by the same medical LCD monitor (The Radio Force MX270W, Eizo Nanao Corporation, Ishikawa, Japan) which has 3.7 MP, $2560 \times 1440$ high-resolution and 27-inch large screen size, under dim-light condition.

Two specialists in oral and maxillofacial radiology assessed the images according to the same protocol. The length and the angulations were noted separately for each side. The measures of two observers were synthetised in one mean measure. The length, thickness, sagittal and transverse angulations of SHC were measured by using the distance, angle mea- 


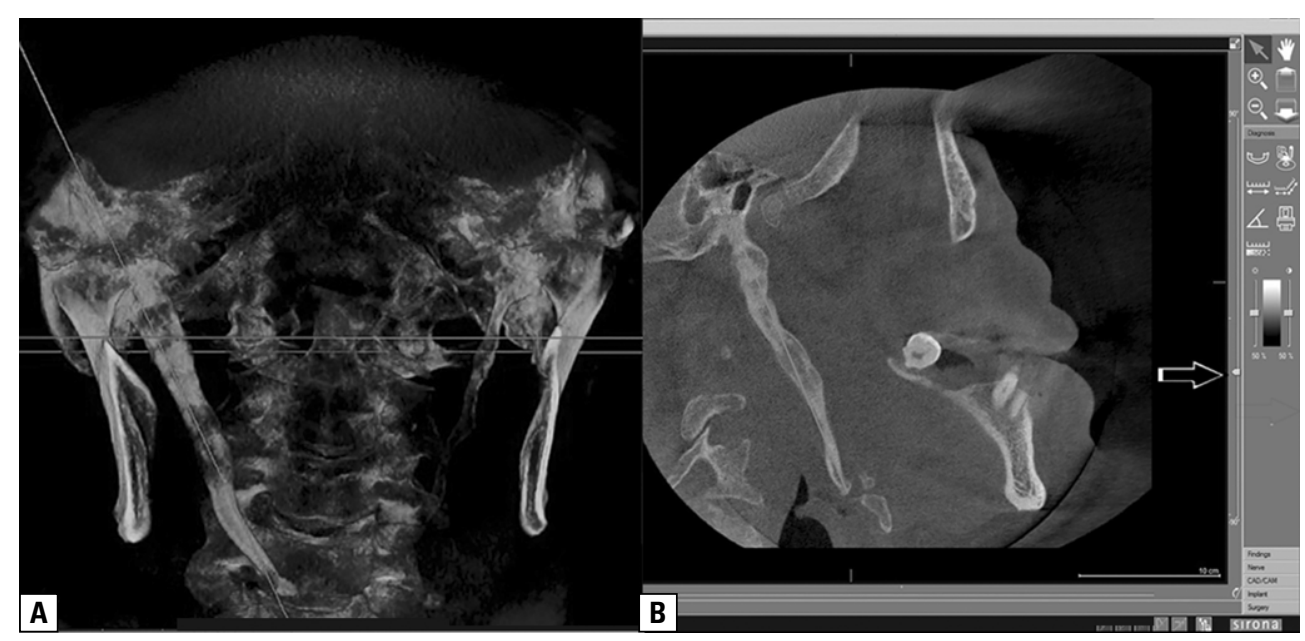

Figure 1. Length measurement; A. Aligning the sagittal plane according to long axis of stylohyoid complex on three-dimensional reconstruction image; B. View from aligned sagittal slice and measurement of the distance between proximal and distal tips of the stylohyoid complex (white arrow: vertical tilt tool).

surement and vertical tilt tools of the software on multiplanar reconstructions (MPR). Morphological variations and ossification degrees were evaluated on MPR and three-dimensional (3D) volume rendering (3DVR) images.

On 3D reconstruction image, sagittal plane was aligned parallel to the line connecting proximal and distal ends of SHC via vertical tilt tool (Fig. 1A). Therefore, long axis of the ossified structure became visible on sagittal MPR slice. On this slice, which displayed the whole SHC on a single image, the distance between proximal and distal tips of the complex was measured as the length of the SHC via distance tool (Fig. 1B). If segmented ossification was detected, the non-ossified parts were measured too. Thickness values at different levels were noted on the same sagittal slice by drawing perpendicular lines to the long axis of the SHC. Maximum length value was recorded as the thickness of that complex (Fig. 2).

The sagittal angle was defined as the anterior angle between the skull base and the long axis of the ossification [1]. The transverse angle was determined as the angle between the line connecting both origin of the SP and the long axis of the process on the coronal images (Fig. 3) [16].

All the 2000 styloid processes were classified according to their shapes as linear, scalariform, moniliform and pseudoduplicated (Fig. 4) [1]. SHCs shorter than $35 \mathrm{~mm}$ were recorded as normal length and those longer than $35 \mathrm{~mm}$ were recorded as elongated [1]. According to their radiological appearance, long SHCs were divided into three groups as



Figure 2. Measurement of thickness. Thickness values at different levels was noted on the sagittal slice by drawing perpendicular lines to the long axis of the stylohyoid complex.

follows: elongated, pseudoarticular and segmented (Fig. 5). Additionally, pursuant to their calcification patterns, SHCs longer than $35 \mathrm{~mm}$ were classified as completely calcified, partially calcified, calcified outline and nodular complex (Fig. 6) [21].

\section{Statistical analysis}

The data were analysed statistically by using SPSS 20.0 (Statistical Package for Social Sciences) for Windows. Data distributions were expressed as means, standard deviations (SD), and ranges. Normality of 


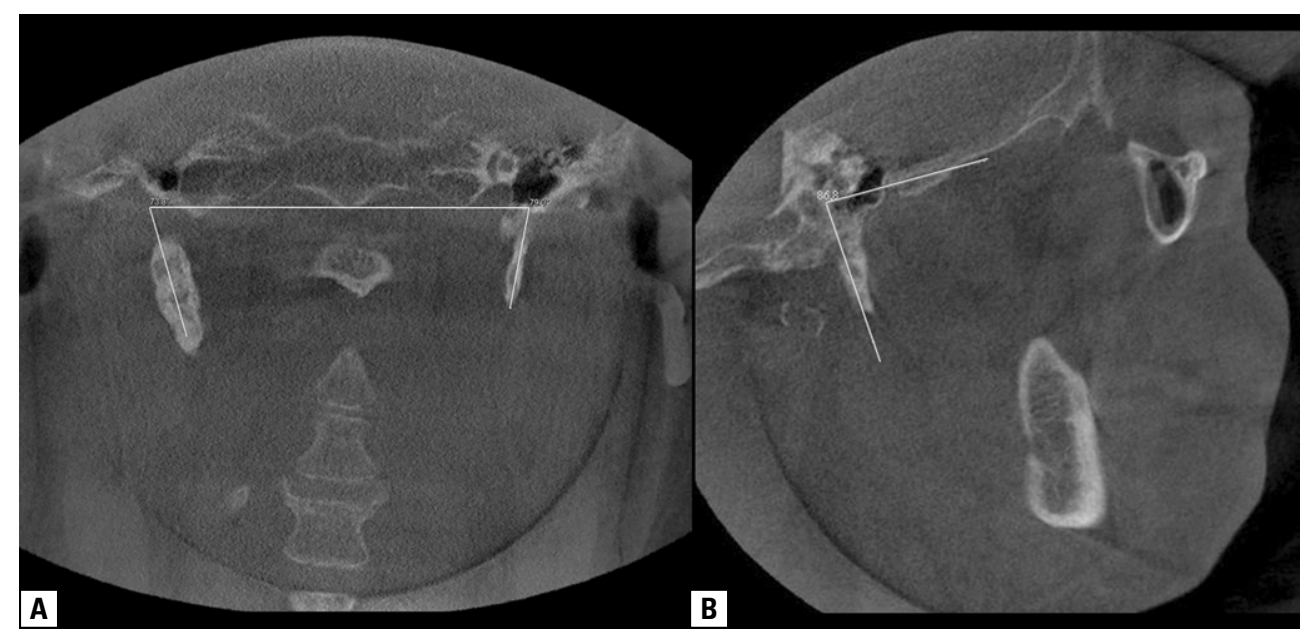

Figure 3. Measurement of sagittal (A) and transverse (B) angles.

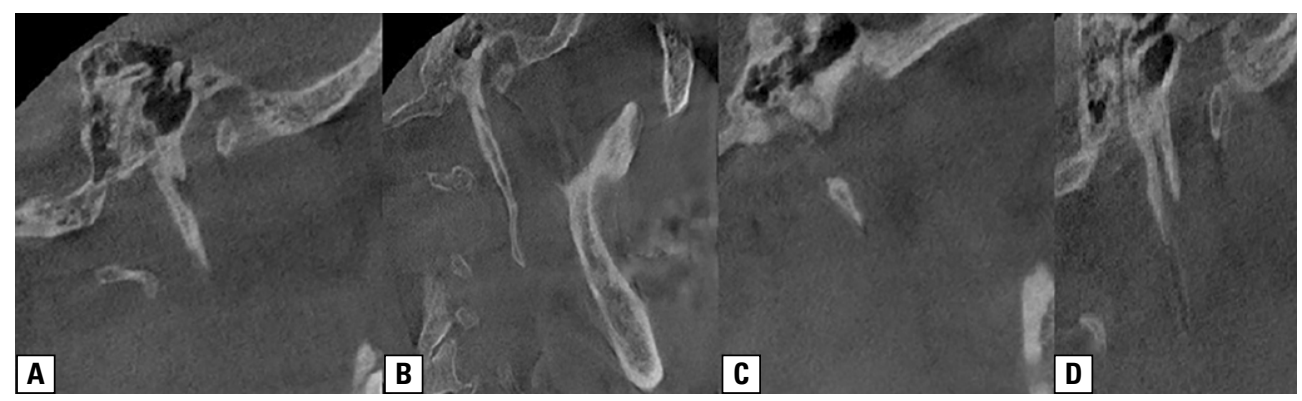

Figure 4. Linear (A), scalariform (B), moniliform (C), pseudoduplicated (D) shape variations.

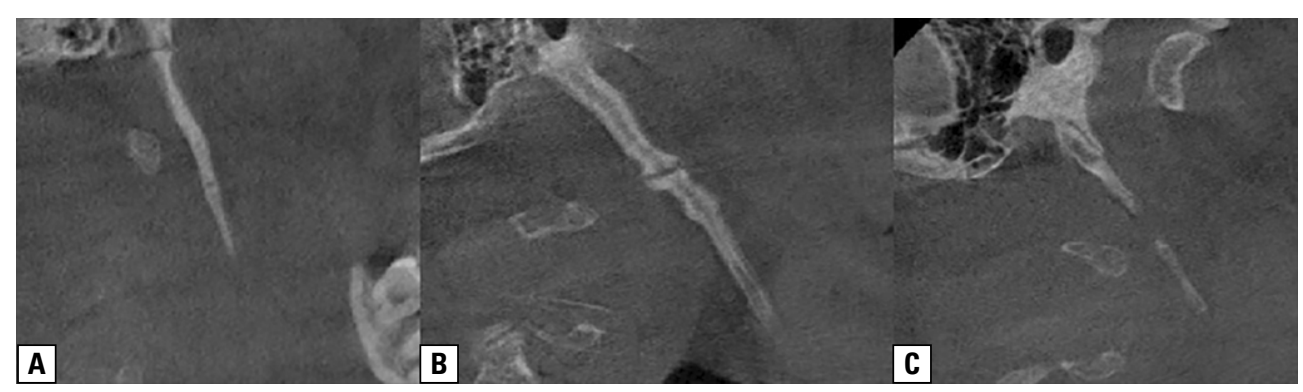

Figure 5. Radiological appearance of stylohyoid complex: elongated (A), pseudoarticular (B) and segmented (C).

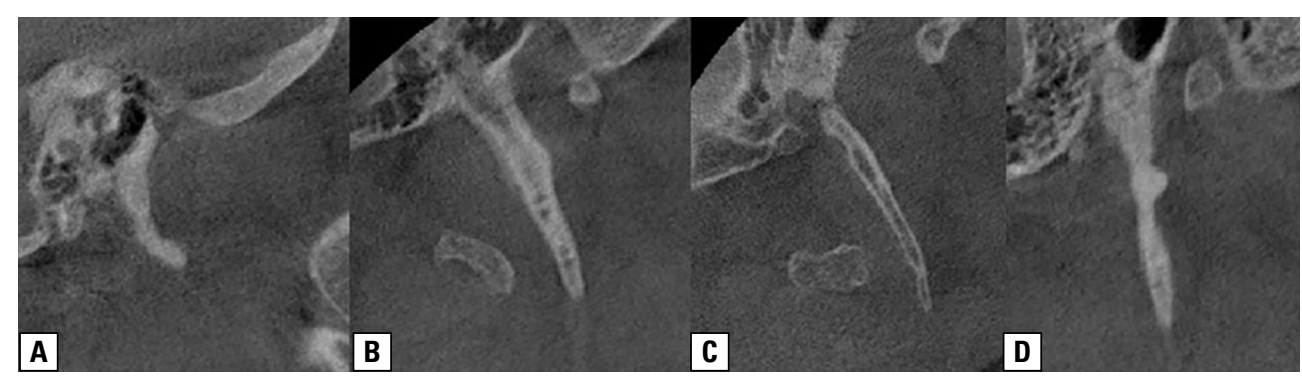

Figure 6. Completely calcified (A), partially calcified (B), calcified outline (C) and nodular complex (D) patterns. 
Table 1. Distribution of normal and elongated stylohyoid complex (SHC) according to side

\begin{tabular}{lccc}
\hline & Right SHC & Left SHC & Total \\
\hline Normal & $639(63.9 \%)$ & $677(67.7 \%)$ & $1316(65.8 \%)$ \\
Elongated & $361(36.1 \%)$ & $323(32.3 \%)$ & $684(34.2 \%)$ \\
Total & $1000(100 \%)$ & $1000(100 \%)$ & $2000(100 \%)$ \\
\hline
\end{tabular}

Table 2. Distribution of normal and elongated stylohyoid complex (SHC) according to gender

\begin{tabular}{lccc}
\hline & Female & Male & Total \\
\hline Normal & $404(70.14 \%)$ & $243(57.31 \%)$ & $647(64.7 \%)$ \\
Elongated & $172(29.86 \%)$ & $181(42.69 \%)$ & $353(35.3 \%)$ \\
Total & $576(100 \%)$ & $424(100 \%)$ & $1000(100 \%)$ \\
\hline
\end{tabular}

Table 3. Mean, minimum and maximum length, thickness, sagittal and transverse angle values according to gender (Student's t-test)

\begin{tabular}{|c|c|c|c|c|c|c|c|}
\hline & \multicolumn{3}{|c|}{ Female } & \multicolumn{3}{|c|}{ Male } & \multirow[t]{2}{*}{$\mathbf{p}$} \\
\hline & Mean \pm SD & Minimum & Maximum & Mean \pm SD & Minimum & Maximum & \\
\hline Length [mm] & $32.75 \pm 8.82$ & 7.40 & 86.20 & $36.37 \pm 10.02$ & 10.3 & 88.70 & $<0.001$ \\
\hline Thickness [mm] & $3.97 \pm 1.22$ & 0.70 & 8.10 & $4.44 \pm 1.31$ & 0.90 & 10.50 & $<0.001$ \\
\hline Sagittal angle $\left[^{\circ}\right]$ & $70.43 \pm 8.14$ & 49.70 & 92.10 & $74.00 \pm 7.99$ & 48.90 & 89.10 & $<0.001$ \\
\hline Transverse angle $\left[^{\circ}\right]$ & $70.34 \pm 6.61$ & 47.10 & 89.10 & $72.23 \pm 6.43$ & 49.10 & 82.20 & $<0.05$ \\
\hline
\end{tabular}

SD - standard deviation

the data distribution was evaluated by KolmogorovSmirnov test. Non-normal data was assessed by using nonparametric tests. When the data distribution was normal, the correlation between the variables was evaluated by Pearson's correlation coefficient, Student's $t$ test, $\chi^{2}$ test and one-way ANOVA. Statistical significance was considered at $p<0.05$.

\section{RESULTS}

According to result of our study, 576 of the 1000 selected patients were female (57.6\%) and 424 were male $(42.4 \%)$. The mean age was 45.95 years. Of the 2000 SHCs studied, 1279 (63.95\%) were longer than $30 \mathrm{~mm}, 684$ (34.2\%) were longer than $35 \mathrm{~mm}$ and 395 (19.75\%) were longer than $40 \mathrm{~mm}$. It was determined that 1316 (65.8\%) of all SHCs were within normal length and 684 (34.2\%) were elongated (> $35 \mathrm{~mm}$ ). The mean age of individuals with normal length of SHC was 45.89; and in those who have elongated SHC it was 46.32. Distribution of normal and elongated SHCs according to side is summarised in Table 1. According to the Wilcoxon test, right SHCs were statistically significantly longer than left SHCs $(p<0.001)$.

Bilateral distribution of $27.3 \%$ and unilateral distribution of $16.2 \%$ of elongated SHCs were recorded. Distribution of normal and the elongated SHCs according to gender is summarised in Table 2. There was a statistically significant difference between gender and SHC length according to Student's t test ( $p<0.001)$. In respect to gender, mean, minimum and maximum SHC length, thickness, sagittal and transverse angle values are summarised at Table 3. There was a statistically significant difference between gender and those variables. Mean thickness value of the normal SHCs were $3.98 \mathrm{~mm}$, whereas the elongated ones were $4.53 \mathrm{~mm}$ thick. There was a positive correlation between length and thickness according to Pearson correlation test $(p<0.005)$.

Patients were divided into five groups according to their age. Patient distribution, mean length, thickness, sagittal and transverse angle values were examined in these groups (Table 4). There was no significant difference between age groups and mean 
Table 4. Patient distribution and length, thickness, sagittal and transverse angle values of stylohyoid complex (SHC) among the age groups

\begin{tabular}{lccccc}
\hline Age group & $\mathbf{N}(\%)$ & $\begin{array}{c}\text { Mean length } \\
{[\mathrm{mm}] \pm \mathbf{S D}}\end{array}$ & $\begin{array}{c}\text { Mean thickness } \\
{[\mathrm{mm}] \pm \text { SD }}\end{array}$ & $\begin{array}{c}\text { Sagittal angle } \\
{\left[{ }^{\circ}\right] \pm \text { SD }}\end{array}$ & $\begin{array}{c}\text { Transverse angle } \\
{\left[{ }^{\circ}\right] \pm \text { SD }}\end{array}$ \\
\hline $18-30$ & $356(17.8 \%)$ & $34.26 \pm 10.72$ & $3.68 \pm 1.30$ & $72.33 \pm 8.55$ & $70.28 \pm 7.59$ \\
$31-40$ & $350(17.5 \%)$ & $34.00 \pm 9.38$ & $4.05 \pm 1.27$ & $72.42 \pm 8.04$ & $70.20 \pm 6.18$ \\
$41-50$ & $418(20.9 \%)$ & $34.01 \pm 9.09$ & $4.32 \pm 1.26$ & $71.83 \pm 8.06$ & $70.76 \pm 6.20$ \\
$51-60$ & $564(28.2 \%)$ & $34.69 \pm 9.33$ & $4.41 \pm 1.27$ & $71.90 \pm 8.11$ & $71.29 \pm 6.36$ \\
$>60$ & $312(15.6 \%)$ & $34.34 \pm 9.13$ & $4.16 \pm 1.30$ & $71.21 \pm 8.69$ & $71.44 \pm 7.80$ \\
\hline
\end{tabular}

SD - standard deviation

length, thickness, sagittal angle and transverse angle according to $\chi^{2}$ test $(p>0.05)$.

The transverse angles were divided into three groups. Less than $65^{\circ}$ were determined as narrow angles, between $65^{\circ}$ and $75^{\circ}$ were normal angles and higher than $75^{\circ}$ were determined as wide angles. Sagittal angles were also divided into three groups: less than $60^{\circ}$, those between $60^{\circ}$ and $70^{\circ}$, and those higher than $75^{\circ}$ and were defined as narrow, normal and wide, respectively. Length and prevalence distribution were examined according to transverse and sagittal angle width (Table 5). There was no significant difference between length and transverse angle values according to one-way ANOVA test $(p>0.05)$. On the other hand, there was a statistically significant but weak correlation between length and sagittal angle values in respect to the Spearman correlation test $(p=0.030, p<0.05)$. All styloid processes in the sample group were examined according to the shape variety. SHCs longer than $35 \mathrm{~mm}$ were classified according to their type and calcification pattern. Results are summarised in Table 6.

There was a statistically significant difference between all morphological variations and age. Scalari-
Table 5. Length and prevalence distribution according to transverse and sagittal angle width

\begin{tabular}{lccc}
\hline & $\begin{array}{c}\text { Length [mm] } \\
\pm \text { standard deviation }\end{array}$ & $\begin{array}{c}\text { Number } \\
\text { ( } \mathbf{n})\end{array}$ & Prevalence \\
\hline $\begin{array}{l}\text { Transverse angle } \\
<65^{\circ} \text { (narrow) }\end{array}$ & $33.44 \pm 9.51$ & 340 & $17 \%$ \\
$65-75^{\circ}$ (normal) & $34.35 \pm 9.52$ & 1125 & $56.25 \%$ \\
$>75^{\circ}$ (wide) & $34.75 \pm 9.50$ & 535 & $26.75 \%$ \\
Sagittal angle & & & \\
$<60^{\circ}$ (narrow) & $33.17 \pm 9.05$ & 700 & $35 \%$ \\
$60-70^{\circ}$ (normal) & $34.42 \pm 9.42$ & 908 & $45.4 \%$ \\
$>70^{\circ}$ (wide) & $37.21 \pm 9.43$ & 392 & $19.6 \%$ \\
\hline
\end{tabular}

form shape, elongated type and nodular calcification pattern have the highest mean age values between the morphological groups, respectively. There was a compelling difference between gender and cited morphological variations. According to their shape variations, linear and scalariform types were more frequent in males, while moniliform and pseudoduplicated types were observed mostly in females. Elongated SHC type was significantly high in males, whereas

Table 6. Distribution of the shape variation, type and calcification pattern

\begin{tabular}{lccccc}
\hline Shape variation & Linear & Scalariform & Moniliform & Pseudoduplicated & Total \\
\hline Number $(\mathrm{n})$ & 1086 & 458 & 93 & 363 & 2000 \\
Percentage & $54.30 \%$ & $22.90 \%$ & $4.60 \%$ & $18.20 \%$ & $100 \%$ \\
\hline Type classification & Elongated & Segmented & Pseudoarticular & & Total \\
\hline Number $(\mathrm{n})$ & 291 & 172 & 221 & & 684 \\
Percentage & $42.55 \%$ & $25.15 \%$ & $32.30 \%$ & & $100 \%$ \\
\hline Calcification pattern & Completely calcified & Partially calcified & Calcified outline & Nodular complex & Total \\
\hline Number $(\mathrm{n})$ & 160 & 202 & 215 & 107 & 684 \\
Percentage & $23.40 \%$ & $29.53 \%$ & $31.43 \%$ & $15.64 \%$ & $100 \%$ \\
\hline
\end{tabular}


Table 7. Shape variation, type and calcification pattern, mean age, gender distribution, mean length, thickness, sagittal and transverse angle values in the sample

\begin{tabular}{|c|c|c|c|c|c|c|c|}
\hline & \multirow[t]{2}{*}{ Mean age } & \multicolumn{2}{|c|}{ Gender, percentage } & \multirow[t]{2}{*}{ Length } & \multirow[t]{2}{*}{ Thickness } & \multirow[t]{2}{*}{ Sagittal angle $\left({ }^{\circ}\right)$} & \multirow[t]{2}{*}{ Transverse angle $\left({ }^{\circ}\right)$} \\
\hline & & Female & Male & & & & \\
\hline \multicolumn{8}{|l|}{ Shape variation } \\
\hline Linear & 46.44 & $51.25 \%$ & $57.7 \%$ & 33.49 & 4.10 & 72.45 & 71.60 \\
\hline Scalariform & 47.27 & $21.15 \%$ & $25.3 \%$ & 37.36 & 4.74 & 71.31 & 71.92 \\
\hline Moniliform & 41.71 & $5.7 \%$ & $3.3 \%$ & 30.51 & 3.38 & 71.75 & 70.36 \\
\hline Pseudoduplicated & 44.5 & $21.9 \%$ & $13.7 \%$ & 33.91 & 3.85 & 71.36 & 71.72 \\
\hline \multicolumn{8}{|l|}{ Type classification } \\
\hline Elongated & 50.80 & $33.6 \%$ & $50.9 \%$ & 41.32 & 4.88 & 74.16 & 71.54 \\
\hline Segmented & 45.83 & $31.6 \%$ & $19.7 \%$ & 43.95 & 4.50 & 71.75 & 70.32 \\
\hline Pseudoarticular & 39.75 & $34.8 \%$ & $29.4 \%$ & 47.29 & 4.03 & 73.03 & 71.32 \\
\hline \multicolumn{8}{|l|}{ Calcification pattern } \\
\hline Completely calcified & 41.97 & $24.65 \%$ & $22.15 \%$ & 43.25 & 4.18 & 73.06 & 71.84 \\
\hline Partially calcified & 45.51 & $30.3 \%$ & $28.6 \%$ & 43.07 & 4.20 & 74.18 & 71.55 \\
\hline Calcified outline & 46.67 & $27.3 \%$ & $35.65 \%$ & 44.99 & 4.82 & 73.25 & 70.65 \\
\hline Nodular complex & 50.46 & $17.8 \%$ & $13.3 \%$ & 45.22 & 3.96 & 71.69 & 70.37 \\
\hline
\end{tabular}

segmented and pseudoarticular types were more frequent in females. Calcified outline was the most prevalent calcification pattern in males, the other patterns were mostly seen in females. There was a significant difference between length and the shape variations. Scalariform shape was the longest, whereas the moniliform type was the shortest. There was a statistically significant but weak correlation between length and types. Pseudoarticular types were longer than elongated and segmented types. The length of the SHC was not notably different between the calcification pattern groups. Lastly, thickness, sagittal and transverse angles were not incomparably different between cited morphological variations (Table 7).

\section{DISCUSSION}

The length, thickness, form and shape of the SHC vary individually [38]. In the literature, SHC is measured by many different methods, and in these studies the normal length varies by $2 \mathrm{~cm}$ ( $\min : 25 \mathrm{~mm}$, max: $45 \mathrm{~mm}$ ) (Table 8). Some authors considered that SHCs longer than $30 \mathrm{~mm}$ cause symptoms in styloid syndromes $[10,17,18,29]$. On the other hand, there were studies emphasizing that length is not the only pathogenic factor $[10,22]$. Fusco et al. [11] stated that as the length increases, the translational capacity at the distal end increases and the possibility of compressing surrounding neuro- vascular tissue during mediolateral complex neck movements increases.

Putative normal length and prevalence values on previous studies are shown in Table 8 . Prevalence of elongated SHC varies between $4.5 \%$ and $63.2 \%$ in studies which proposed $30 \mathrm{~mm}$ as normal length [5, 13, $18,22,28,30,35,37,40]$. Andrei et al. [1] determined the normal length of $\mathrm{SHC}$ as $35 \mathrm{~mm}$ and they reported the prevalence of elongated SHC as $40 \%$ in their CBCT study. Despite the widespread occurrence of elongated SHC, they emphasized that clinical manifestations were few. The obtained incidence of elongated SHC in our research is in close proximity with their study.

In studies in which normal SHC length was assumed to be $40 \mathrm{~mm}$, the elongated SHC prevalence was $21.2 \%$ by Monsour and Young [23], and $9.7 \%$ by Basekim et al. [2]. The results of the researches were quite varied. Unlike previous studies, Kent et al. [19] measured the SHC length by rotating the image until the long axis of the SHC was parallel to the viewing, as we did in our study. They suggested that this length measurement method may account for longer SHC values. In our study, in which the number of samples were higher than in the other studies and SHC was examined in three dimensions, the frequency of individuals with SHC longer than $30 \mathrm{~mm}$ was $63.95 \%$; in $34.20 \%$ of subjects SHC was longer than $35 \mathrm{~mm}$ and in $19.75 \%$ it was longer than $40 \mathrm{~mm}$. 
Table 8. The studies performed by various researchers show the putative normal length value, the prevalence, the average length, the number of included patients and the examination method of stylohyoid complex (SHC) ossification

\begin{tabular}{|c|c|c|c|c|c|c|}
\hline Researcher & Publishing date & $\begin{array}{l}\text { Normal length } \\
{[\mathrm{mm}]}\end{array}$ & Prevalence & $\begin{array}{l}\text { Mean length } \\
{[\mathrm{mm}]}\end{array}$ & Sample size & $\begin{array}{l}\text { Examination } \\
\text { method }\end{array}$ \\
\hline Kaufmann & 1970 & 30 & $28 \%$ & $\begin{array}{c}29.5 \text { (left) } \\
29.9 \text { (right) }\end{array}$ & 484 & $\mathrm{OPG}$ \\
\hline Frommer & 1974 & Unspecified & Unspecified & 31.7 & 241 & Cadaver \\
\hline 0'Carroll & 1984 & Unspecified & $78.5 \%$ & Unspecified & 479 & OPG \\
\hline Monsour & 1986 & 40 & $21.2 \%$ & 29.2 & 549 & $\mathrm{OPG}$ \\
\hline Lengele & 1988 & 30 & $29 \%$ & 26 & 246 & Macerated skull \\
\hline Ferrario & 1990 & 25 & $84.4 \%$ & Unspecified & 286 & $\mathrm{OPG}$ \\
\hline Jung & 2004 & 45 & Unspecified & 28 & 1000 & $\mathrm{OPG}$ \\
\hline Basekim & 2005 & 40 & $9.7 \%$ & 28.3 & 138 & CT \\
\hline Onbas & 2005 & Unspecified & $32 \%$ & 26.8 & 283 & MSCT \\
\hline Okabe & 2006 & 45 & $15 \%$ & 36.7 & 659 & $\mathrm{OPG}$ \\
\hline Vougiouklakis & 2006 & Unspecified & $0.9 \%$ & Unspecified & 1215 & Cadaver \\
\hline Ramadan & 2007 & 30 & Unspecified & 27 & 100 & CT \\
\hline Gokce & 2008 & 30 & $7.7 \%$ & Unspecified & 750 & $\mathrm{OPG}$ \\
\hline Andrei & 2012 & 35 & $40 \%$ & 35 & 44 & СВCT \\
\hline \multirow[t]{2}{*}{ Andrade } & 2012 & Unspecified & $76 \%$ & 32.98 (left) & 50 & OPG. \\
\hline & & & & 33.5 (right) & & $\begin{array}{l}\text { Cephalometric } \\
\text { radiograph }\end{array}$ \\
\hline Centruion & 2013 & 30 & $\begin{array}{c}42 \% \text { (OPG) } \\
63 \% \text { (CBCT) }\end{array}$ & Unspecified & 100 & OPG, CBCT \\
\hline Ilguy & 2013 & 28 & Unspecified & 25.3 & 69 & СВCT \\
\hline Reddy & 2013 & 30 & $29.62 \%$ & 36.7 & 260 & $\mathrm{OPG}$ \\
\hline \multirow[t]{2}{*}{ Natsis } & 2014 & 33 & $25.2 \%$ (left) & 24.7 (left) & 149 & Dry skull \\
\hline & & & 25.2 (right) & $28.3 \%$ (right) & & \\
\hline Oztunc & 2014 & 30 & $54 \%$ & Unspecified & 208 & СВСТ \\
\hline Patil & 2014 & 30 & $14 \%$ & 25.8 & 114 & Dry skull \\
\hline Rheem & 2014 & Unspecified & $6.12 \%$ & Unspecified & 147 & СВCT \\
\hline Shaik & 2014 & 30 & $63.2 \%$ & 36.7 & 1162 & OPG \\
\hline \multirow[t]{2}{*}{ Vadgaonkar } & 2015 & 30 & $4.5 \%$ & 18.2 (left) & 110 & Dry skull \\
\hline & & & & 17.8 (right) & & \\
\hline
\end{tabular}

CT — computed tomography; CBCT — cone beam computed tomography; MSCT — multislice computed tomography; OPG — ortopantomography

Okabe et al. [25] performed a study using panoramic radiographs of 659 patients. They reported that among 80 -year-old patients in their study, 55\% had SHC above $35 \mathrm{~mm}$. They suggested that the length criterion had to be reassessed for elderly individuals and the SHCs longer than $45 \mathrm{~mm}$ should be regarded as elongated. Our results showed no significant difference between the age groups and the length of SHC. We think that the difference between these studies was caused by the difference in the average age of the sample group.
In panoramic radiographs, the structures located medial to the focal trough have higher magnification and distortion [17, 23]. SHC, especially its distal end, is located medial to the image layer. Three-dimensional imaging provides more accurate assessment of the spatial orientation of the SHC than two-dimensional radiographs [12]. CBCT imaging was found to be more suitable to diagnose SHC ossifications than panoramic images [5]. In the literature, studies with $\mathrm{CBCT}$ on the imaging of SHC were few in number 
compared to those made with panoramic radiography. Additionally, there were some studies done with $\mathrm{CT}$.

In a study in which $138 \mathrm{CT}$ images were evaluated, the SHC prevalence over $40 \mathrm{~mm}$ was observed to be $9.7 \%$ [2]. The SHC prevalence longer than $40 \mathrm{~mm}$ was found to be higher in our study. Onbas et al. [27] reported the elongated SHC prevalence of $32 \%$ in their study which was conducted by CT. Because of the superimposition of the radiopaque structures at the base of the skull, they emphasized that conventional imaging methods might be difficult to determine the dimension and orientation of SHC while CT allows measuring the accurate length of the complex.

Centruion et al. [5] evaluated the panoramic radiographs and CBCT images of 100 patients together and found that the elongated SHC prevalence was $42 \%$ in panoramic radiographs and $63 \%$ in $\mathrm{CBCT}$ images. According to this result, they suggested that CBCT imaging was superior to panoramic radiographs in stylohyoid complex evaluation. Although the number of samples used in this research was quite high compared to the study, SHC prevalence above $30 \mathrm{~mm}$ was found to be $63.95 \%$, similar to their result.

Oztunc et al. [28] stated 13\% unilateral and 33\% bilateral elongation of the SHC in their research. However, we detected $16.2 \%$ unilateral and $27.3 \%$ bilateral cases.

Stylohyoid complex length and gender relations were investigated in some studies. In accordance with our study, Eagle [6], Gozil et al. [14], Okabe et al. [25] and Ilguy et al. [16] stated that SHC length was longer in males than females. On the other hand, there were studies reporting that there was no statistically significant difference between length and gender $[1,5,17,26]$.

Onbas et al. [27] reported that there was no statistically significant difference between SHC length, sagittal, transverse angle and gender. On the contrary, in our study, the length of the SHC was measured higher; sagittal and transverse angle values were measured wider in male individuals.

Carroll [4] and Ferrario et al. [9] reported a positive correlation between SHC length and age. Conversely, in our study, no significant difference was observed between age and length. Jung et al. [17] emphasized in their study in which the study group were divided into two age groups, younger and older than 35 years, that the length of the styloid process very slowly but significantly increase with age. In our investigation, patients were divided into five age groups, and the length of the SHC did not show a statistically significant difference between these groups. In agreement with our study, Lengele and Dhem [22], Centruion et al. [5] and Sancio-Goncalves et al. [36] reported there was no significant difference between SHC length and age. Moreover, we measured the scalariform shape, the elongated type and the nodular calcification pattern as the highest mean age groups among the morphological variations which has not been evaluated before.

There are limited numbers of studies about the sagittal plane angle of the SHC in the literature. Onbas et al. [27] chose the angle between the long axis of the SP and the skull base line connecting the nasion and the opisthion as the reference point for sagittal angle measurement, reported the mean sagittal angle of $93.5^{\circ}$. Ramadan et al. [33] referenced the Mc Rae line for sagittal angle measurement and observed the mean sagittal angle of $63.6^{\circ}$. Andrei et al. [1] defined the anterior angle between the long axis of the SP and the skull base as the sagittal angle in their $\mathrm{CBCT}$ study and reported the mean of this angle of $53.98^{\circ}$. In our study, in which the sagittal angle was defined as the angle between the skull base and the long axis of the SHC, the mean measured sagittal angle was $72.24^{\circ}$. A notable difference is seen when all studies are considered together. This may be due to the different reference points used for evaluation or the different sample sizes.

Ilguy et al. [16] measured the posterior sagittal angle as anteroposterior angle between the vertical line passing from the cranial base of the process which was vertical to the Frankfort plane and the long axis of SHC. They found a positive correlation between the SHC thickness and this angle, suggesting that the thicker SHC was directed more anteriorly. In contrast to llguy et al. [16], the sagittal angle was measured in the anterior direction of SHC and there was a significant positive correlation between anterior sagittal angle and thickness in our study.

As the anterior sagittal angle increases, SHC is directed posteriorly. It has been reported that increased sagittal angle may lead to posterior orientation of elongated SHC, therefore cranial nerves IX-XII, internal carotid artery, and internal jugular vein may be compressed between SHC and atlas [27, 33, 34]. In our study, wide sagittal angle group have the longest mean length value. We can conclude that as the anterior 
sagittal angle gets wider, the length of the SHC tends to increase. Andrei et al. [1] found a weak positive correlation between sagittal angle and length consistent with our results. The prevalence of narrow sagittal angle was found to be $35 \%$ in our research, this narrow angle group have the shortest mean SHC length. Additionally; it has been reported that elongated SHC with narrow anterior sagittal angle may irritate anatomical structures in the parapharyngeal region [1].

Ilguy et al. [16] stated that there was no statistically significant difference between age, length, thickness, and transverse angle, but reported a positive correlation between age and sagittal angle. In our study, no significant relationship was found between age groups and those variables. In the same study, in accordance with our results, llguy et al. [16] found a positive correlation between thickness and length.

In the literature, there is a consensus that as the medial angulation gets more narrow it may produce some complaints by compression of adjacent structures $[2,18]$. Basekim et al. [2] reported the narrow transverse angle prevalence of $11.5 \%$, while we observed it to be $17 \%$ (Table 8 ). In both studies, the percentage of subjects assigned to the narrow angle groups were the lowest compared to the other study groups. We can assume that narrow transverse angle is not common. There was no significant difference between length and transverse angle values in our study, which is in accordance with the study of Andrei et al. [1], Basekim et al. [2] and Onbas et al. [27] who reported the mean transverse angle of $66.74^{\circ}, 69.4^{\circ}$ and $72.7^{\circ}$, respectively and they stated there was no significant relationship between transverse angle and length. These results are consistent with our study in which the mean transverse angle value is $70.81^{\circ}$.

Kursuoğlu et al. [20] reported that elongated SHC and calcified outline type were observed most frequently according to radiological appearance and calcification patterns of SHCs. Parallel to their study, the incidence of elongated SHC was $42.55 \%$ and calcified outline type was $31.43 \%$, as the highest in our study. Similarly, llguy et al. [15] found most commonly the elongated SHC. On the other hand, they reported in the same study that most frequent calcification patterns of SHC was partial calcification.

Andrei et al. [1] classified SHC according to 3D morphology; but they have not evaluated the distribution of these types. To our knowledge, this is the first study evaluating the shape variations of SHC particularly. According to our results, the linear shape was the most common, while the moniliform shape was the least common. Linear and scalariform types were more frequent in males, while moniliform and pseudoduplicated types were observed mostly in females. Scalariform shape was the longest, whereas the moniliform type was the shortest (Table 7).

Petrovic et al. [32] evaluated gender and SHC morphology. They classified the SHC at six groups which were: normal appearance with up to $40 \mathrm{~mm}$, normal appearance longer than $40 \mathrm{~mm}$, bent, segmented, pseudoarticulated and styloid process with stylohyoid ligament distally ossified to the hyoid bone. Although the classification criteria were different, in compliance with our study they reported that elongated SHC type was observed mostly in males. Unlikely the segmented type seen more often in females in our study (31.6\% in females, $19.7 \%$ in males), Petrovic et al. [32] reported that this type was observed more frequently in males.

\section{CONCLUSIONS}

According to our results, age has not any effect on SHC length, thickness, sagittal and transverse angles. All these parameters of SHC except age were found higher in men than in women. We found a positive correlation between SHC length and thickness. We observed that as the anterior sagittal angle gets wider, SHC tends to get longer. However, there was not a significant difference between transverse angle and length. The most observed morphological variations were linear shape, elongated type and calcified outline pattern. Scalariform shape, elongated type and nodular calcification pattern have the highest mean age values. Pseudoarticular type was the longest group. SHC is an anatomical entity with a wide variety of morphological aspects. Further detailed morphological studies on the classification made by considering the different properties will contribute to the literature.

\section{REFERENCES}

1. Andrei F, Motoc AG, Didilescu AC, et al. A 3D cone beam computed tomography study of the styloid process of the temporal bone. Folia Morphol. 2013; 72(1): 29-35, indexed in Pubmed: 23749708.

2. Başekim CC, Mutlu H, Güngör $A$, et al. Evaluation of styloid process by three-dimensional computed tomography. Eur Radiol. 2005; 15(1): 134-139, doi: 10.1007/s00330-004-2354-9, indexed in Pubmed: 15221266.

3. Camarda AJ, Deschamps C, Forest D, et al. I. Stylohyoid chain ossification: a discussion of etiology. Oral Surg Oral Med Oral Pathol. 1989; 67(5): 508-514, indexed in Pubmed: 2497419. 
4. Carroll O. Calcification in the stylohyoid ligament. Oral Surg Oral Med Oral Pathol. 1984; 58(5): 617-621, indexed in Pubmed: 6595625

5. Centurion BS, Imada TSN, Pagin O, et al. How to assess tonsilloliths and styloid chain ossifications on cone beam computed tomography images. Oral Dis. 2013; 19(5): 473-478, doi: 10.1111/ odi.12026, indexed in Pubmed: 23107068.

6. Eagle WW. Elongated styloid processes: report of two cases. Arch Otolaryngol. 1937; 25(5): 584-587, doi: 10.1001/archotol.1937.00650010656008

7. Eagle WW. Elongated styloid process; further observations and a new syndrome. Arch Otolaryngol. 1948; 47(5): 630-640, indexed in Pubmed: 18894764.

8. Eagle WW. Symptomatic elongated styloid process; report of two cases of styloid process-carotid artery syndrome with operation. Arch Otolaryngol. 1949; 49(5): 490-503, indexed in Pubmed: 18131173.

9. Ferrario VF, Sigurtá D, Daddona A, et al. Calcification of the stylohyoid ligament: incidence and morphoquantitative evaluations. Oral Surg Oral Med Oral Pathol. 1990; 69(4): 524-529, indexed in Pubmed: 2326043.

10. Fini G, Gasparini G, Filippini F, et al. The long styloid process syndrome or Eagle's syndrome. J Craniomaxillofac Surg. 2000; 28(2): 123-127, doi: 10.1054/jcms.2000.0128, indexed in Pubmed: 10958426.

11. Fusco DJ, Asteraki S, Spetzler RF. Eagle's syndrome: embryology, anatomy, and clinical management. Acta Neurochir (Wien). 2012; 154(7): 1119-1126, doi: 10.1007/s00701-012-1385-2, indexed in Pubmed: 22638594

12. Gayathri G, Elavenil P, Sasikala B, et al. 'Stylo-mandibular complex' fracture from a maxillofacial surgeon's perspective--review of the literature and proposal of a management algorithm. Int J Oral Maxillofac Surg. 2016; 45(3): 297-303, doi: 10.1016/j. ijom.2015.09.020, indexed in Pubmed: 26701324.

13. Gokce C, Sisman Y, Sipahioglu M. Styloid process elongation or Eagle's syndrome: is there any role for ectopic calcification? Eur J Dent. 2008; 2: 224-228.

14. Gözil R, Yener N, Calgüner E, et al. Morphological characteristics of styloid process evaluated by computerized axial tomography. Ann Anat. 2001; 183(6): 527-535, doi: 10.1016/S0940-9602(01)80060-1, indexed in Pubmed: 11766524.

15. Ilgüy $M$, Ilgüy $D$, Güler N, et al. Incidence of the type and calcification patterns in patients with elongated styloid process. J Int Med Res. 2005; 33(1): 96-102, doi: 10.1177/147323000503300110, indexed in Pubmed: 15651721.

16. Ilgüy $D$, Ilgüy $M$, Fişekçioğlu $E$, et al. Assessment of the stylohyoid complex with cone beam computed tomography. Iran J Radiol. 2012; 10(1): 21-26, doi: 10.5812/iranjradiol.4891, indexed in Pubmed: 23599709.

17. Jung $T$, Tschernitschek $H$, Hippen $H$, et al. Elongated styloid process: when is it really elongated? Dentomaxillofac Radiol. 2004; 33(2): 119-124, doi: 10.1259/dmfr/13491574, indexed in Pubmed: 15314005

18. Kaufman SM, Elzay RP, Irish EF. Styloid process variation. Radiologic and clinical study. Arch Otolaryngol. 1970; 91(5): 460-463, indexed in Pubmed: 5442737

19. Kent DT, Rath TJ, Snyderman C. Conventional and 3-dimensional computerized tomography in Eagle's syndrome, glossopharyngeal neuralgia, and asymptomatic controls. Otolaryngol Head Neck Surg. 2015; 153(1): 41-47, doi: 10.1177/0194599815583047, indexed in Pubmed: 25917666.

20. Kursoglu P, Unalan F, Erdem T. Radiological evaluation of the styloid process in young adults resident in Turkey's Yeditepe University faculty of dentistry. Oral Surg Oral Med Oral Pathol Oral Radiol Endod. 2005; 100(4): 491-494, doi: 10.1016/j.tripleo.2005.05.061, indexed in Pubmed: 16182171.

21. Langlais RP, Miles DA, Van Dis ML. Elongated and mineralized stylohyoid ligament complex: a proposed classification and report of a case of Eagle's syndrome. Oral Surg Oral Med Oral Pathol. 1986; 61(5): 527-532, indexed in Pubmed: 3459129.
22. Lengelé BG, Dhem AJ. Length of the styloid process of the temporal bone. Arch Otolaryngol Head Neck Surg. 1988; 114(9): 1003-1006, indexed in Pubmed: 3408565.

23. Monsour PA, Young WG. Variability of the styloid process and stylohyoid ligament in panoramic radiographs. Oral Surg Oral Med Oral Pathol. 1986; 61(5): 522-526, indexed in Pubmed: 3086788.

24. Natsis K, Repousi E, Noussios G, et al. The styloid process in a Greek population: an anatomical study with clinical implications. Anat Sci Int. 2015; 90(2): 67-74, doi: 10.1007/s12565-014-0232-3, indexed in Pubmed: 24664363.

25. Okabe S, Morimoto Y, Ansai T, et al. Clinical significance and variation of the advanced calcified stylohyoid complex detected by panoramic radiographs among 80 -year-old subjects. Dentomaxillofac Radiol. 2006; 35(3): 191-199, doi: 10.1259/dmfr/12056500, indexed in Pubmed: 16618854.

26. Omnell KA, Gandhi C, Omnell ML. Ossification of the human stylohyoid ligament: a longitudinal study. Oral Surg Oral Med Oral Pathol Oral Radiol Endod. 1998; 85(2): 226-232, indexed in Pubmed: 9503461.

27. Onbas O, Kantarci M, Murat Karasen R, et al. Angulation, length and morphology of the styloid process of the temporal bone analyzed by multidetector computed tomography. Acta Radiol. 2005; 46(8): 881-886, indexed in Pubmed: 16392614.

28. Oztunç H, Evlice B, Tatli U, et al. Cone-beam computed tomographic evaluation of styloid process: a retrospective study of 208 patients with orofacial pain. Head Face Med. 2014; 10: 5, doi: 10.1186/1746-160X-10-5, indexed in Pubmed: 24528515.

29. Palesy P, Murray GM, De Boever J, et al. The involvement of the styloid process in head and neck pain -- a preliminary study. J Oral Rehabil. 2000; 27(4): 275-287, indexed in Pubmed: 10792587.

30. Patil S, Ghosh S, Vasudeva N. Morphometric study of the styloid process of temporal bone. J Clin Diagn Res. 2014; 8(9): AC04-AC06, doi: 10.7860/JCDR/2014/9419.4867, indexed in Pubmed: 25386413.

31. Pereira FL, Filho LI, Pavan AJ, et al. Styloid-stylohyoid syndrome: literature review and case report. J Oral Maxillofac Surg. 2007. 65(7): 1346-1353, doi: 10.1016/j.joms.2006.07.020, indexed in Pubmed: 17577500

32. Petrović S, Jovanović I, Ugrenović S, et al. Morphometric analysis of the stylohyoid complex. Surg Radiol Anat. 2017; 39(5): 525-534, doi: 10.1007/s00276-016-1757-z, indexed in Pubmed: 27734098.

33. Ramadan SU, Gokharman D, Tunçbilek I, et al. Assessment of the stylohoid chain by 3D-CT. Surg Radiol Anat. 2007; 29(7): 583-588, doi: 10.1007/s00276-007-0239-8, indexed in Pubmed: 17657398.

34. Ramadan SU, Gökharman D, Koşar P, et al. The stylohyoid chain: CT imaging. Eur J Radiol. 2010; 75(3): 346-351, doi: 10.1016/j. ejrad.2010.04.021, indexed in Pubmed: 20462718.

35. Reddy RS, Kiran CS, Madhavi NS, et al. Prevalence of elongation and calcification patterns of elongated styloid process in south India. J Clin Exp Dent. 2013: e30-5, doi: 10.4317/jced.50981.

36. Sancio-Gonçalves FC, de Abreu MH, Netto Soares JM, et al. Stylohyoid complex ossification in temporomandibular disorder: a casecontrol study. J Prosthet Dent. 2013; 109(2): 79-82, doi: 10.1016/ S0022-3913(13)60019-0, indexed in Pubmed: 23395332.

37. Shaik MA, Kaleem SM, Wahab A, et al. Prevalence of elongated styloid process in Saudi population of Aseer region. Eur J Dent. 2013; 7(4): 449-454, doi: 10.4103/1305-7456.120687, indexed in Pubmed: 24932120

38. Stafne EC, Hollinshead WH. Roentgenographic observations on the stylohyoid chain. Oral Surg Oral Med Oral Pathol. 1962; 15: 1195-1200, indexed in Pubmed: 13978697.

39. Steinmann EP. Styloid syndrome in absence of an elongated process. Acta Otolaryngol. 1968; 66(4): 347-356, indexed in Pubmed: 5734501.

40. Vadgaonkar R, Murlimanju BV, Prabhu LV, et al. Morphological study of styloid process of the temporal bone and its clinical implications. Anat Cell Biol. 2015; 48(3): 195-200, doi: 10.5115/ acb.2015.48.3.195, indexed in Pubmed: 26417479.

41. Vougiouklakis T. Overview of the ossified stylohyoid ligament based in more than 1200 forensic autopsies. J Clin Forensic Med. 2006; 13(5): 268-270, doi: 10.1016/j.jcfm.2005.09.006, indexed in Pubmed: 16442338. 